\title{
Comparison Of Middle Ear Soft Tissue Density Of Chronic Otitis Media With Cholesteatoma By CT
}

\author{
Sermin Tok ${ }^{1}$, Naime Altınkaya², Fulya Ozer ${ }^{3}$ \\ ${ }^{1}$ Department of Radiology, Faculty of Medicine, Mersin University, Turkey \\ ${ }^{2}$ Department of Radiology, Baskent University Faculty of Medicine, Adana Teaching and Research Center, Adana, Turkey. \\ ${ }^{3}$ Department of Otorbinolaryngology, Baskent University Faculty of Medicine, Adana Teaching and Research Center, Adana, Turkey.
}

\begin{abstract}
Objective: Chronic otitis media is the infection of the middle ear and mastoid air cells. Cholesteatoma is keratinized squamous epithelium formation in the middle ear. Although the two diseases may be recognized with clinical examination, sometimes it may not be possible. While treatment of chronic otitis media includes antibiotic therapy or surgery, cholesteatoma is treated surgically. In this study, we aimed whether quantitative measurement of the soft tissue density in the middle ear on temporal bone CT may be used as a criterion for discrimination of chronic otitis media and cholesteatoma.
\end{abstract}

Materials and Methods: A total of 45 patients were included in the study. Multi-slice CT images were obtained in supine position for temporal bone CT. The soft tissue density was measured using free hand and circle region of interest (ROI) techniques on temporal bone CT examinations.

Results: A statistically significant difference was not detected between cholesteatoma and COM with regard to $\mathrm{HU}$ values on temporal bone CT in ROC curve. $\mathrm{P}$ value and Mann Whitney $U$ was not statistically significant.

Conclusion: As a result, soft tissue density measurement is not statistically significant for differential diagnosis of COM and cholesteatoma.

Keywords: Chronic otitis media, cholesteatoma, CT, soft tissue density.

\section{Introduction}

Chronic otitis media (COM) is common all over the world and among the most common infectious diseases. This disease includes the infection and flux of middle ear and mastoid together with tympanic membrane perforation. Treatment may include antibiotic therapy or surgery ${ }^{[1]}$.

Cholesteatoma is an inflammatory disease of the temporal bone. Cholesteatoma is usually seen in the middle ear, develops as a result of keratinized squamous epithelium in the middle ear. Migration is believed to arise either from pars flaccida or less commonly from pars tensa through a defect in tympanic membrane. It probably coexists with infection and Eustachian tube dysfunction ${ }^{[2]}$.
Discrimination of COM and cholesteatoma is important as operation type varies. Discrimination of the two diseases may not always be possible through clinical examination. Many criteria have been used for radiologic discrimination on temporal CT to date however discrimination cannot be done in some cases.

In this study, we evaluated whether quantitative measurement of the soft tissue density in the middle ear on temporal bone CT may be used as a criteria for discrimination of chronic otitis media and cholesteatoma.

\section{Materials and Methods}

A total of 72 cases who were obtained temporal bone CT
Correspondence: Sermin Tok, MD. Department of Radiology, Mersin University Faculty of Medicine, Mersin Ciftlikkoy, 33343, Yenisehir, Mersin, Turkey.

E-mail: sermintok@hotmail.com

Received: February 14, 2017 Accepted: March 25, 2018
Online available at:

www.entupdates.or DOI: 10.32448 /entupdates. 45896 
and who underwent an operation in our hospital between the dates of June 2011 and January 2015 were evaluated retrospectively. Thirteen cases which had a history of a previous operation, 10 cases below 18 years and 4 cases which had tympano-sclerosis findings on CT were excluded from the study. Forty-five cases between 18-63 years were included in the study.

Multi-slice CT images were obtained in supine position using a MS-CT device (General Electric; Optima 580, Chicago,USA) at $0,625 \times 16 \mathrm{~mm}$ collimation , $0.7 \mathrm{sec}$ rotation time, at table movement at $9,37 \mathrm{~mm} /$ pose gantri rotation, 160 effective mAs and $120 \mathrm{kV}$ parameters. The initial images were transferred to a different work station. 3000 WW / $500 \mathrm{WL}$ values were used for imaging. The soft tissue density was measured using free hand and circle region of interest (ROI) techniques on temporal bone CT examinations. Measurements were performed 3 times and the average was used in the primary analysis. It is also known that cholesteatoma can be associated to chronic middle ear infection and that cholesteatoma often co-exists with cholesteatoma. So the measurements were done on axial plane, from the regions where cholesteatoma or COM was detected area. Age, gender, operation side, diagnosis of COM and cholesteatoma were recorded on Microsoft Excel file for each patient.

\section{Statistical analysis}

For the analysis of the data, statistical tests were performed using SPSS 17.0 statistical software (SPSS, Inc., Chicago, IL, USA), using the following statistical tests: one way ANOVA, Krukal Wallis, Post Hoc test and Mann-whitney U test. They were explained Mean \pm standard deviation $(\mathrm{p}>0.05$ in Kolmogorov-Smirnov test or Shapira-Wilk $(n<30)$ ) when continuous variables were normal. They were explained median when the continuous variables were not normal. Receiver operating characteristic curves (ROC curves) were constructed and the areas under curve (AUC) as well as the sensitivity, and the specificity were calculated for CSA and MLD. The statistical significance of all tests was set to a $\mathrm{p}<0.05$.

\section{Results}

There were $21 \mathrm{COM}$ and 24 cholesteatoma cases according to pathology results. Of the cases, 15 had left-sided COM and 6 had right-sided COM, 14 had left-sided cholesteatoma and 10 had right-sided cholesteatoma. HU values were detected as 11,55-59,39 in COM cases and 25,36-70,58 in cholesteatoma cases (figure r). Mean HU of COM was found as 44,2833, mean HU of cholesteatoma was found as 47,4608 . A statistically significant difference was not detected between cholesteatoma and COM with regard to $\mathrm{HU}$ values on temporal bone $\mathrm{CT}$ in ROC curve. $\mathrm{P}$ value was detected as 0,873 according to Mann Whitney $\mathrm{U}$ test and this value was not statistically significant.

\section{Discussion}

Cholesteatoma is a tumor of the middle ear which is histopathologically benign, clinically aggressive and invasive. It may lead to hearing loss, vestibular dysfunction, facial paralysis and fatal intracranial complications ${ }^{[3]}$. The pathologic features of the disease were first described by Cruveilhier, a French pathologist, in 1829. Cruveilhier reported that cholesteatoma is an avascular tumor originating from subarachnoid space cells and described it as "pearl- like tumor" macroscopically ${ }^{[4]}$. It is an epidermoid cyst histopathologically. The lumen of the cyst is filled with desquamated epithelial debris. The subepithelial layer includes inflammatory processes composed of cholesterol crystals and giant cells and round cells ${ }^{[5]}$.

Chronic otitis media is the infection which develops due to lowly virulent microorganisms or middle ear aeration and Eustachian tube malfunction. It may also develop within the adhesive otitis media cholesteatoma ${ }^{[5]}$.

Diagnosis of COM is done based on otoscopic examination. CT may be used for making a diagnosis and operation plan ${ }^{[6]}$.



Figure 1. Soft tissue density measurement at mastoid antrum level in a case with right-sided cholesteatoma. Mean $\mathrm{HU}$ value was detected as 54,54 
CT evaluated middle ear bones, bone destructions, facial canal involvement, labyrinth fistula, soft tissue localizations in the studies until today ${ }^{[1,2,6]}$. Temporal CT may also evaluate temporal bone complications and cerebellar abscess, extra-dural abscess or otitic hydrocephalus ${ }^{[7]}$.

CT was developed in the 1970s by Sir Godfrey Hounsfield and Allan Mac Leod Cormack. The technology Works by acquiring planar X-ray images (or projections) taken at various degrees of rotation around a patient or specimen. These data are then reconstructed, typically with a filtered back projection algorithm, to produce a 3-dimensional array of radio density values. Frequently, these data are calibrated to Hounsfield units (HU) which indicate radiodensity, and are calculated using the equation below:

$$
\mathrm{HU}=1000 \times(\mu \mathrm{x}-\mu \text { water }) / \mu \text { water }
$$

\section{References}

1. Rogha M, Hashemi SM, Mokhtarinejad F, Eshaghian A, Dadgostar A. Comparison of PreoperativeTemporal Bone CT withIntraoperativeFindings in Patients with Cholesteatoma. Iran J Otorhinolaryngol. 2014; 26: 7-12.

2. Manasawala M, Cunnane ME, Curtin HD, Moonis G. Imaging findings in auto-atticotomy. AJNR. 2014; 35: 182-5.

3. Maniu A, Harabagiu O, Perde Schrepler M, Cătană A, Fănuţă B, Mogoantă CA. Molecularbiology of cholesteatoma. Rom J Morphol Embryol. 2014; 55: 7-13.

4. Scott M. Epidermoid tumour (tumorperlée, cholesteatoma) of the fourth ventricle: case report and review of literature. J Neurol Neurosurg Psychiatry. 1974; 37: 1329-32.

5. Valvassori's Imaging of the Head and Neck. 2005; 2ndedition: 68-89
Air's values are $-1,000 \mathrm{HU}$. Values of water are $0 \mathrm{HU}$. Bone's values are upto 3000 HU. Softtissues' values are between $+100-+300 \mathrm{HU}^{[8]}$.

Despite the presence of the studies trying soft tissue characterization with MRI and diffusion MRI, no studies are available investigating whether soft tissue density may be used for discrimination of the two diseases ${ }^{[9]}$.

In conclusion, we detected that soft tissue density measurement is not statistically significant for differential diagnosis of COM and cholesteatoma. Cholesteatoma may accompany to COM frequently, so the statiscal results maybe due to that.

6. Yildirim M, Ozmen CA, Gun R, Yorgancılar E, Akkus Z, Topcu I. An Evaluation of Preoperative Computed Tomography on Patients with Chronic Otitits Media. Indian J Otolaryngol Head Neck Surg. 2012, 64: 67-70.

7. Jerbi Omezzine S, Dakkem M, Ben Hmida N, Saidi M, Ben Rhouma $\mathrm{K}$, Driss N et al. Spontaneous cholesteatoma of the external auditory canal: the utility of CT. Diagn Interv Imaging. 2013; 94: 438-42.

8. Wathen CA, Foje N, van Avermaete T, Miramontes B, Chapaman $\mathrm{SE}$, Sasser TA et al. In vivo X-ray computed tomographic imaging of soft tissue with native, intravenous, or oral contrast. Sensors (Basel). 2013; 27;13: 6957-80.

9. Baráth K, Huber AM, Stämpfli P, Varga Z, Kollias S. Neuroradiology of cholesteatomas. AJNR. 2011;32:221-9

This is an open access article distributed under the terms of the Creative Commons Attribution-NonCommercial-NoDerivs 3.0 Unported (CC BYNC-ND3.0) Licence (http://creativecommons.org/licenses/by-nc-nd/3.0/) which permits unrestricted noncommercial use, distribution, and reproduction in any medium, provided the original work is properly cited.

Please cite this article as: Tok S, Altınkaya N, Ozer F. Comparison of middle ear soft tissue density of Chronic Otitis Media with Cholesteatoma by CT. ENT Updates 2018;8(2): 79-81. 